\section{脊髄損傷に対する FES：最近の動向}

秋田大学医学部附属病院リハビリテーション部

島田 洋一, 松永 俊樹

同 整形外科

\section{三澤 晶子, 櫻場 乾 相澤 俊朗, 井樋 栄二}

\section{はじめに}

脊髄損傷により生じた四肢麻痺, 対麻痺では, 機能向上の手段として, 社会生活に適応するため のリハビリテーション（以下，リハ）や車椅子， 杖，装具などの補助具がある。これらにより，あ る程度の活動性は得られるが, 患者はその機能に 必ずしも満足しているわけではなく，健常に近い 再建を望んでいる，四肢麻痺であれば，自分で飲 食, 書字, 整容などができ, 対麻痺であれば起 立，歩行が可能になることを望んでいる．現在， 健常により近い機能を再建する有用な手段とし て, 麻痺した四肢を電気刺激で動かし，コンピュ 一夕制御によって目的とした機能を再建する機能 的電気刺激 (functional electrical stimulation, FES）がある。この技術は，1963 年，C 4 四肢麻 痺の指伸筋を刺激して手の opening を制御し, finger hinge splint と組み合わせて応用されたの が最初である。その後, 刺激電極, 刺激装置, コ ンピュータ，センサーのめざましい進歩により再 建できる機能も増え，より実用的となった。これ までのところ，脊髄損傷に対する FES は，上肢 では飲食, 書字, 整容 ${ }^{1 \sim 6)}$, トランスファーが, 下肢では起立・着席, 起立維持が実用的であり, 歩行は症例により差がある7 12). 本稿では, 最近 の FES の動向について述べ，次世代の新技術で ある機能的磁気刺激 (functional magnetic stimulation, FMS）についても言及する。

\section{FES システム}

FES は, 使用する電極によってシステムの複
雑さ, 得られる機能が異なる. 電極には, 表面電 極, 経皮的埋め込み電極, 完全埋め込み電極があ る. 表面電極は, 簡便であるが, 深部筋を刺激で きないこと，貼り替える度に刺激に対する反応が 変わること, 知覚が残存している場合, 疼痛を生 じるなどの問題がある。しかし，無侵襲なため, 特に下肢機能再建にはハイブリッド FES として 広く用いられている. 経皮的埋め込み電極は選択 的で, 深部筋の刺激も容易で, 刺激に対する反応 が安定しており，外部からの制御も容易である. 一方, 電極が皮膚を貫通するため, 美容, 感染の 危険性, 断線, 移動などが問題となる. 完全埋め 込み電極には, 筇膜に縫い付ける epimysial 電 極, 神経束にシリコン膜を使って巻き付ける cuff 電極, 神経上膜に縫い付ける epineural 電極があ る.これらの完全埋め込み電極は, 消毒処置の煩 わしさや感染の危険もなく, 理想的であるが, 生 体外から生体内への多チャンネル信号伝達システ ム, 動作制御システムの問題がある. 現在は, そ れぞれの電極, システムがもつ利点を生かしなが ら臨床応用されており, 主なものについて述べ る.

\section{1. 表面電極システム}

すでに商品化されているものもあり，侵襲の低 さから導入しやすい. しかし, 貼付の煩わしさと 一定しない筋反応のため, 訓練室レベルでは有用 だが，実生活に用いる患者が少なく，臨床成績の 検討も短期のものが多い.

上肢再建では, Nathan が開発したらせん状の cock up splint の内面に表面電極を配置した HANDMASTER が四肢麻痺上肢の再建に用い られている13)。

下肢では，Parastep が有用である6). Lee ら ${ }^{11)}$ は脊髄損傷入院患者 714 例中 180 例に使用し, $12.8 \%$ で痤性六進, 全身状態の悪化で drop out したが, $42.8 \%$ では平均 10.6 分起立し， $17.8 \%$ で平均 $25.8 \mathrm{~m}$ 歩行できたと報告している. 全体 からみた歩行可能率は $4.5 \%$ で，同様に表面電極 を用いた Kralj ら ${ }^{12)}$ が 500 例中 $5 \%$ で歩行可能た ったのと同じ結果であった。このシステムの有用 性は十分な検証が行われており, 確立したものと 
なっている。

また，表面電極による再建は，不全対麻痺に対 して有用である。痙性抑制, 筋力増強などの治療 的目的のみならず，起立・歩行再建にも用いられ ている．欧米では，リハプログラムの一環に組み 込まれている施設もあり ${ }^{8}$, cost の問題が解決さ れれば，広く普及して良い方法である ${ }^{11)}$.

表面電極を併用した rowing system は，多く の施設で開発, 使用されており, 訓練機器として 心肺機能の改善に役立っている ${ }^{14)}$.

\section{2. 経皮的埋め込み電極システム}

Akita FES Project では, 1990 年以降, 仙台 FESプロジェクトが開発した $\phi 25 \mu \mathrm{m}$ の SUS 316 L 極細硬質ステンレス線を 19 本撚りに してテフロン被覆した経皮的埋め込み電極を用い てきた. 電極が electroslag remelting process （ESR）によって精製されるため, 非金属含有物 がほとんどないことから断線が極めて少ない ${ }^{15)}$. 本システムによる成績は, これまで種々報告して きた.

FES は古くから行われているが，いずれも短 期成績の報告で, 長期にわたったものは極めて少 ない.同じ電気刺激による装置である心臓ペース メーカーが装置のメンテナンスなどの関係から長 期成績がある程度はっきりしているのとは対照的 である．経皮的埋め込み電極を使用するようにな って初めて長期成績を論じられるようになった。 しかし，これらハイテク装置を臨床応用している 施設は, 国内外とも限られているという背景があ る. 心臓ペースメーカー同様, 一般に体内に埋め 込まれた電極, 刺激装置などの耐用性を考えると 3 年は安定していることが要件となる.そして, 長期成績を左右する要因として，1）電極の耐用 性，2）刺激装置の耐用性，3）日常生活における 有用性，4）使用頻度などが挙げられる。そこで 当科で経皮的埋め込み電極を刺入し，機能再建を 行い, 術後 3 年以上経過し, FES, TESによる 治療を継続している春髄損傷例について検討し た。症例は, 13 例（男性 9 例，女性 4 例）であ る. 手術時年齢は, 平均 28.3 歳（2６9 歳）で あり，うち 3 例は成長途上の小児であった。麻痺
は，完全麻痺 7 例，不全麻痺 6 例である。再建 は，上肢を 1 例，下肢を 12 例に行った。経過観 察期間は平均 6.2 年（3～10.7 年）である。これ らについて，経過観察時において電気刺激による 適切な反応を維持している生存電極数を調查し た. その結果，再建時刺入した経皮的埋め込み電 極数は，1 例あたり平均 22.6 本（8～40 本）で, そのうち経過観察時に生存していた電極数は，平 均 16.2 本（6～26本）であった。生存率は平均 71.4\%（40.7〜 100\%）であった．成長に伴う電 極障害が危惧される小児例では，再建時平均 22 本 $(19 \sim 27$ 本) が, 経過観察時は平均 12.3 本 (9 17 本) の生存であり, 生存率も $57.7 \%$ (40.7〜85\%) と低かった. 13 例中 3 例では電極 の追加刺入を行った。このように長期的にみて も，ほほ満足な結果といえる。

経皮的埋め込み電極を用いた再建は，四肢麻痺 上肢での円筒握り，鍵握りによる飲食，書字，整 容動作は自立できる実用レベルであり，これまで のリハゴールを越えることができる，対麻痺で は，不全損傷例では TES 効果による起立・歩行 の獲得，完全損傷例での起立・着席動作，起立維 持が実用レベルである。

\section{3. 完全埋め込みシステム}

FES システムの理想型であり，ハイテクノロ ジーの結集である．欧米では，すでに商品化さ れ，多くの臨床例をもつシステムもある。

FREE HAND SYSTEM は Peckham ら ${ }^{1,2)}$ が 8 チャンネルの完全埋め込み電極と装置を開発 し，腱移行術と FES を併用して上肢機能を再建 した，患者は肩を動かすことによって角度計の信 号データを経由して刺激の on/off を行う.患者 自身で FES 装置を操作し，手の円筒握りと鍵握 り動作を随意的に行うことができる．このシステ ムの臨床評価について Wuolle ら ${ }^{3)}$ は 8 施設, 34 例の調查を行い, 満足度 $87 \%$ で, ADL 改善 $87 \%$ ，自立 $81 \%$ と良好な成績を述べている。す でに FDAによって認可され，200 例近く臨床応 用されている。商業上も成功を収めており， FES 装置としては，現在最も確立したものであ る。開発者である Peckham ら ${ }^{1)} は ， 51$ 例の 
C 5,6 四肢麻痺例の 3 年以上の長期成績について 報告している，参加施設は，米国 8, 英国，オー ストラリアがそれぞれ 1 である。それによれば, 90\%以上が日常生活で使用しており, grasprelease 機能も 49 例で改善していた。最長例は術 後 12.9 年であり, 驚異的な生存率と有効率であ った。これは，同じ完全埋め込み式電気刺激装置 である心臓ペースメーカーと比較すると，制御す るチャンネル数など, より複雑な FES 装置にも かかわらず，単純なペースメーカーに劣らない長 期成績であり，商業ベースで成り立っている要因 である。

一方，四肢の動作再建だけでなく，排尿コン トロールなども同時に行う Praxis multifunctional implanted system の臨床応用も行わ れている. 22 チャンネルのうち 18 本を下肢動作 再建に，残り 4 本を排尿コントロールに用いてい る9). 2 例に応用し, swing through gaitでそれ ぞれ $87 \mathrm{~m}, 223 \mathrm{~m}$ の歩行再建に成功している.

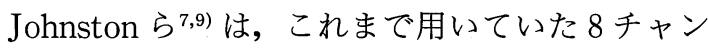
ネルシステムより起立, 歩行共に延びており優れ ていると報告している．また，Benda ら ${ }^{16)}$ は同 時に行った膀胱直腸再建の有用性を述べている.

これからの FES システムは四肢機能, 膀胱直 腸，痙性抑制，疼痛管理などの多機能同時制御の 方向に向かっていくと考える.

脊髄損傷患者に対する FES で最も実用的で, 得られる機能も良好で，施行数も多いのは排尿コ ントロールシステムである。その中でも, Brindley のシステムは最も普及している ${ }^{17)} .1982$ 年以 来すでに 1,600 例以上の臨床例がある．初期の 500 例の検討では， 72 例 (14.4\%) に failure が あり，そのうち 56 例は刺激装置を修復している。 9 例は装置の交換を行った. 53 例のうち 21 例 （39.6\%）では再度壊れ，12 例で修復した. 12 例 中 3 例は 3 度壊れ，修復もしくは交換した。 424 例では，良好な使用状況で，11例は不明，21例 は死亡，45例は他の理由で使用していなかっ た ${ }^{17)}$. このように, 本システムは多くの臨床例を 有し，しかも長期に安定した成績を残している. この技術を発展させた VOCARE bladder system
（NeuroControl, USA）は，より優れたものとな っている. Creasey ら ${ }^{18)}$ は, Vocare system に よる anterior nerve root刺激と posterior nerve root rhizotomyを 23 例に行い, 19 例で $200 \mathrm{ml}$ 以上の排尿, 15 例で $50 \mathrm{ml}$ 以上の残尿という優 れた結果を報告している. 同時に 15 例で排便操 作に要する回数が減少したと述べている．その 上, system failure は 1/19.6 implant per year と十分実用的であった。 今後, 多くの春髄損傷患 者に普及することが予想され, 本邦でも適応施設 を拡充する必要がある。

\section{制＼cjkstart御}

電気刺激によっていくら強い筋活動が得られて も目的とする動作を制御できなければ，臨床応用 はできない.そのため，この分野には多くの medical engineer が参画し, 制御技術を開発し ている. 角度計, 加速度計, 圧センサー, 張力セ ンサーなどの基本的なものから，より高度になっ てきている.

筋疲労を抑え, 転倒などの合併症を予防するた めの closed loop control は高度な再建には必須 である. 我々は, 完全対麻痺の起立維持に独自の 張力センサーシステムを開発し, 臨床応用に成功 した ${ }^{19)}$. その後, Artificial neural network を応 用するシステムを構築し, 歩行周期を 2 軸加速度 センサーで検知し, 片麻痺の歩行を再建した ${ }^{20)}$. 同様に，各国でFESに対する Artificial neural networkの応用が進められている ${ }^{21)}$.また, Praxis systemには portable motion analysis system を内蔵した sensor pack が用いられてい る ${ }^{22)}$.これは, 将来体内に制御システムを完全に 埋め込む計画となっている。体内埋め込みシステ ムはすでに FREE HAND SYSTEM の制御のた め, 関節角度計が手関節に埋め込まれている2).

さらに，EEGを用いる Brain-computer Interface（BCIs）は，新たなコントロール技術であ る. Broord ら ${ }^{23)}$ は 8〜13 Hz の Mind switchを 用いており，Wolpaw ら ${ }^{24)}$ は別の strategy を用 いている. Craig ら ${ }^{25)}$ は Environmental control system（ECS）を提唱している。このように, 


\section{機能的磁気刺激（FMS）}

近年, 電気刺激に代わるものとして, 磁気刺激 が注目されている。これまで，MRIに代表され る画像診断, 神経機能検査に応用されてきた.し かし，磁気は疼痛を伴わずに深部の神経・筋を刺 激することができることから，障害された機能を FES 同様に再建する機能的磁気刺激 (functional magnetic stimulation, FMS）の臨床応用が始ま っている. Lin らは 8 例の脊髄損傷患者の呼吸訓 練 $^{26)}$ や消化管機能27) の改善に応用している. 我々は, 春髄損傷ラットの急性筋萎縮に対する FMS の効果を検討し, 従来の電気刺激に代わり 得ることを報告した ${ }^{28)}$.

この分野では, 米国 Alfred Mann Foundation が開発した BION system が最も臨床的である。 局麻下で注射針から motor point にリードなしの 超小型電極を留置可能で, 侵襲が小さく, 完全埋 め込み式であるため管理が容易で, 画期的なシス テムといえる。刺激コイルは体表外部より刺激を 伝達する ${ }^{29}$. システム上, まだ治療的刺激 (therapeutic stimulation) の域を出ないが，われわれ が共同研究に加わり, FMS として発展させてい く計画である。すでに動物実験を経て臨床応用間 近である.FMSの進歩は, 古くからリ八医療に 広く用いられてきた電気刺激に多くの分野で取っ て代わる可能性がある.この方面の技術進歩の早 さから考えると，その時期は決して遠くない.

\section{おわりに}

Donaldson $ら^{30)}$ は，英国の 2 つの脊髄損傷工 ニットにおける 1982１999 年のデータを解析し， 全患者数 1,795 例のうち完全対麻痺は 522 例で, そのうち 115 例 (22\%) が FES 再建基準を満た したが, 安全で自立した機能が得られるのは 15 例, 自宅でも使用するのは 7 例で, 結論として約 10\%の完全対麻痺が FES の適応となることを述 べている．毎年多くの新たな春髄損傷患者が発生 し, 医学の進歩を切望している. 損傷脊髄再生技 術と再建医療としての FES, FMS はこの分野の

\section{文献}

1) Peckham $\mathrm{PH}$, Keith $\mathrm{MW}$, Kilgore $\mathrm{KL}$, Grill $\mathrm{JH}$, Wuolle KS, Thrope GB, Gorman P, Hobby J, Mulcahey MJ Carroll S, Hentz VR, Wiegner A: Efficacy of an implanted neuroprosthesis for restoring hand grasp in teteraplegia: a multicenter study. Arch Phys Med Rehabil 2001; 82 : 1380-1388

2) Peckham PH, Kilgore KL, Keith MW, Bryden AM, Bhadra N, Montague FW: An advanced neuroprosthesis for restoration of hand and upper arm control using an implantable controller. J Hand Surg 2002; $27: 265-276$

3) Wuolle KS, Van Doren CL, Bryden AM, Peckham PH, Keith MW, Kilgore KL, Grill JH : Satisfaction with and usage of a hand neuroprosthesis. Arch Phys Med Rehabil 1999; 80 : 206-213

4) Matsunaga $T$, Shimada $Y$, Sato M, Hatakeyama $K$, Chida S, Itoi E, Misawa A, Ito H, Sakuraba T, IIzuka $\mathrm{K}$ : Clinical experience of functional electrical stimulation for restoration of tetraplegic hand function. Proc 8th IFESS $2003 ; 84-85$

5) Shimada $Y$, Chida $S$, Matsunaga $T$, Misawa A, Ito H, Sakuraba T, Sato M, Hatakeyama K, Itoi E: Grasping power by means of functional electrical stimulation in a case of $\mathrm{C} 6$ complete tetraplegia. Tohoku J Exp Med 2003; 201 : 91-96

6) Klose KJ, Jacobs PL, Broton JG, Guest RS, Needham BM, Lebwohl N, Nash MS, Green BA : Evaluation of a training program for persons with SCI paraplegia using the parastep 1 ambulation system : Part 1. ambulation performance and anthropometric measures. Arch Phys Med Rehabil 1997; 78: 789-793

7) Johnston TE, Betz RR, Smith BT, Mulcahey MJ : Implanted functional electrical stimulation: an alternative for standing and walking in pediatric spinal cord injury. Spinal Cord 2003 ; 41 : 144-152

8) Bajd T, Cikajlo I, Savrin R, Erzin R, Gider F : FES rehabilitation systems for re-education of walking in imcomplete spinal cord injured persons. Neuromoduration $2000 ; 3:$ 167-174

9) Johnston TE, Smith BT, Betz RR, Benda BJ, Mulcahey MJ, Davis R, Barriskill A : Initial experiences with upright mobility using the Praxis multifunctional implanted FES system. Proc 8th IFESS 2003; 26-29

10) Davis R, Patrick J, Barriskill A : Development of functional electrical stimulators utilizing Cochler implant technology. Med Eng Phys 2001 ; 23 : 61-68

11) Lee BS, Shin HI, Kim SM, Kim BS: Walking training with functional electrical stimulation: 3 years experience in Korean National Rehabilitation Hospital. Proc 8th IFESS $2003 ; 39-40$

12) Kralj A, Bajd T (eds) : Functional Electrical Stim- 
ulation: Standing and Walking after Spinal Cord Injury. CRC Press Inc, Boca Raton, 1989

13) Alon G, McBride $K$ : Persons with $C 5$ or $C 6$ tetraplegia achieve selected functional gains using a neuroprosthesis. Arch Phys Med Rehabil 2003 ; 84 : 119-124

14) Wheeler GD, Andrews B, Lederer R, Davoodi R, Natho K, Weiss C, Jeon J, Bhambhani Y, Steadward RD: Functional electrical stimulationassisted rowing: increasing cardiovascular fitness through function electric stimulation rowing training in persons with spinal cord injury. Arch Phys Med Rehabil 2002; 83 : 1093-1099

15) Shimada $Y$, Sato K, Kagaya H, Konishi N, Miyamoto S, Matsunaga $\mathrm{T}$ : Clinical use of percutaneous intramuscular electrodes for functional electrical stimulation. Arch Phys Med Rehabil 1996; 77 : 1014-1018

16) Benda BJ, Houdayer T, Creasey G, Betz RB, Smith BT, Johnston TE, Davis R: The Praxis FES system and bladder management in patient with spinal cord injury. Proc 8th IFESS 2003 ; 41-45

17) Brindley GS: The first 500 sacral anterior root stimulators: implant and their repair. Paraplegia $1995 ; 88: 5-9$

18) Creasey GH, Grill JH, Korsten M, U HS, Betz R, Anderson R, Walter $\mathrm{J}$ : An implantable neuroprosthesis for restoring bladder and bowel control to patients with spinal cord injury. Arch Phys Med Rehabil 2001; 82: 1512-1519

19) Shimada $Y$, Sato $K$, Matsunaga $T$, Tsutsumi $Y$, Misawa A, Ando S, Minato T, Sato M, Chida S, Hatakeyama K: Closed-loop control using a stretch sensor for restoration of standing with functional electrical stimulation in complete paraplegia. Tohoku J Exp Med 2001; 193 : 221-227

20) Shimada $Y$, Ando S, Chida S : Functional electrical stimulation. Artif Life Robot 2000 ; 4: 212-219

21) Sepulveda F, Granat MH, Cliquet A Jr: Gait restration in spinal cord injured subject via neuromuscular electrical stimulation controlled by an artificial neural network. Artif Organs 1998; 21 : 46-62

22) Jasiewicz JM, Worringham CJ, Barriskill A, Parker $\mathrm{S}$ : The development of a portable motion analysis system using FES motion. Proc 8th IFESS 2003; 61-64

23) Broord P, Craig A, Barriskill A, Nguyen H : Developing a hands-free neuroprosthesis command system. Proc 8th IFESS 2003; 7-9

24) Wolpaw JR, Birbaumer N, Heetderks WJ, McFarland DJ, Peckham PH, Schalk G: Brain-computer interface technology: a review of the first international meeting. IEEE Trans Rehabil Eng 2000; 8: 164-173

25) Craig A, Moses P, Tran Y, McIsaac P, Kirkup L : The effectiveness of a hands-free environmental control system for the profoundly disabled. Arch Phys Med Rehabil 2002; 83: 1-4

26) Lin VW, Hsiao IN, Zhu E, Perkash I : Functional magnetic stimulation for conditioning of expiratory muscles in patients with spinal cord injury. Arch Phys Med Rehabil 2001; 82: 162-166

27) Lin VW, Nino-Murcia M, Frost F, Wolfe V, Perkish I : Functional magnetic stimulation of the colon in persons with spinal cord injury. Arch Phys Med Rehabil 2001; 82: 167-173

28) Sakuraba $T$, Shimada $Y$, Matsunaga $T$, Minato $T$, Ito $\mathrm{H}$, Sato M, Hatakeyama $\mathrm{K}$, Chida S, lizuka K : Preventing acute atrophied muscles by therapeutic magnetic stimulation. Proc 8th IFESS 2003 ; 302305

29) Davis R, Mishler KF, Canfield D, Zilberman Y, Schulman J: Surgical technique to insert and retrieve Bion (microstimulator) safety neer deep nerves for functional electrical stimulation. Proc 7th IFESS $2002 ; 191-192$

30) Donaldson $\mathrm{N}$ de N, Wood DE, McFadden C: Functional standing for paraplegics: is it a sensible goal? Proc 7th IFESS 2002 ; 9-11 